\title{
Better discriminated bar-press avoidance at short intertrial intervals
}

\author{
JACK PEARL AND JOHN J. FITZGERALD \\ STERLING-WINTHROP RESEARCH INSTITUTE
}

Four groups of rats received discriminated avoidance training in Skinner boxes at intertrial intervals (ITIs) of $0.2,1,5$, or $30 \mathrm{sec}$. As ITI decreased avoidances and bar presses per min. increased and differences among groups persisted when ITI was then increased to $30 \mathrm{sec}$. for all groups. The better avoidance at short ITIs was attributed to response perseveration after shock and the results were related to those obtained without an exteroceptive warning stimulus (Leaf, 1965) and to those with discontinuous shock (D'Amato, Keller, \& DiCara; 1964; Hurwitz, 1964).

Mention has often been made of difficulties in establishing discriminated avoidance responses in Skinner boxes (D'Amato \& Schiff, 1964; Chapman \& Bolles, 1964; Meyer, Cho, \& Wesemann, 1960; Pearl \& Edwards, 1962). That the number of avoidance responses can be increased by decreasing intertrial interval (ITI) seemed to merit more research (Pearl, 1963). The present study investigated whether the improvement in avoidance continued when ITI was further decreased and whether any initial improvement persisted when ITI was then increased.

\section{Method}

Subjects

Ss were 32 Sprague-Dawley male rats weighing from 170 to $210 \mathrm{gm}$.

Apparatus and Procedure

The Skinner box and the shock generator were previously described (Pearl \& Edwards, 1962). The shock generator was set at the $3 \mathrm{ma}$ calibration and the CS was an increase in white noise level from 61 to $80 \mathrm{db}$. The CS was programmed to act alone for $20 \mathrm{sec}$. and then with the UCS for 5 sec. A bar press ended the CS and prevented delivery of the UCS or ended both the CS and UCS. Holding the bar down had no effect on experimental operations: The bar had to be released and pressed again to have any effect. There were 200 trials of training on each of five consecutive days. On days 1-4 ITI was different for four groups of eight Ss each: $0.2,1,5,30$ sec. as measured from the end of a CS to onset of the next CS. On Day 5 ITI was $30 \mathrm{sec}$, for all groups.

Included are means for percentage of avoidance responses, latencies for trials on which there was an avoidance response (avoidance latency), and bar presses per min. Bar presses per min. rather than total presses are presented because the former showed a relationship to ITI more clearly than the latter. Records of escape responses and of escape latencies are not included because they were unrelated to ITI. Differences in performance among groups on each day were evaluated with the Kruskal-Wallis analysis of variance. Results

The left hand section of Fig. 1 shows means for percentage of avoidance responses; the middle section, avoidance latencies; the right hand section, presses per min. Inspection of the curves suggests that as ITI decreased avoidances increased, avoidance latencies decreased, and presses per min. increased. Avoidances on Days 1-4 increased significantly as ITI decreased (ps $<.05$ on each day) and, except perhaps for the 0.2 sec. ITI group, the same relationship held on Day 5 when ITI was $30 \mathrm{sec}$, for all groups $(p<.01)$. Although the relationship of avoidance latencies to ITI was statistically equivocal, avoidance latencies tended to decrease as ITI decreased $(p<.05$ on Day 3; ps $>.10$ on other days). The differences among groups in bar presses were significant on each day (ps $<.01$ ). On Days 1-4 the differences in presses can be attributed to the artifact that most presses were being made to shock or shortly thereafter and that the duration of the training session for short ITI groups was less than those for long ITI groups. However, at least some effects of prior ITI training persisted on Day 5 when ITI was the same for all groups.

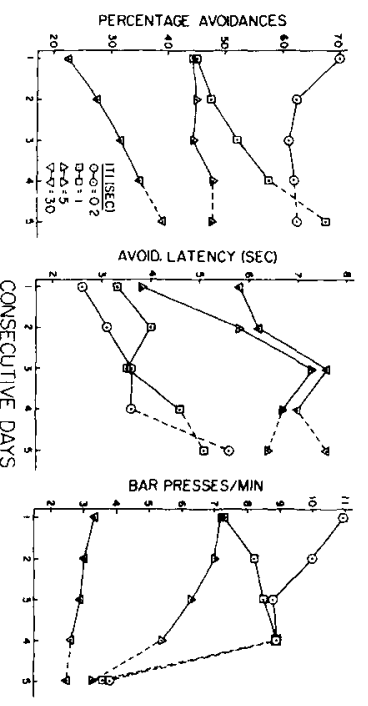

Fig. 1. Percentage of avoidance responses, avoidance latencies, and bar presses per min. as a function of ITI. (On Days 1-4 ITI was different for each of four groups; on Day 5 it was the same for all groups.) 


\section{Discussion}

The major finding of this study was that avoidance continued to improve as ITI was decreased to approximately $1 \mathrm{sec}$. and that the improvement persisted when ITI was then increased. The improvement may be related to the fact that perseveration of responding after shock is more likely to result in avoidance responses when the ITI is short than when it is long and that this pattern of responding, once established, may persist when ITI is then increased. Agreeing with the results of the present study are those of a previous study dealing with ITI interval and discriminated avoidance (Pearl, 1963) and those of a study without an exteroceptive warning stimulus (Leaf, 1965)。

Interestingly, the use of short ITIs may in part account for the better avoidance with discontinuous shock as opposed to continuous shock (D'Amato et al, 1964; Hurwitz, 1964). The continuous shock group in these studies received training at long ITIs in a manner similar to the procedure of the present study. But the discontinuous shock groups were trained with brief periodic shocks given every few sec, and the CS acted till the rats responded. So during a given trial of training there was a brief interval between successive shocks and no interval between shocks and the continually acting CS.

\section{References}

Chapman, J. A., \& Bolles, R. C. Effects of UCS duration on classical avoidance learning of the bar-press response. Psychol. Rep., 1964, 14, 559-563.

D'Amato, M. R., Keller, D. M., \& DiCara, L. Facilitation of discriminated avoidance learning by discontinuous shock. J. comp. physiol. Psychol., 1964, 58, 344-349.

D'Amato, M. R., \& Schiff, D. Long-term discriminated avoidance performance in the rat. J. comp. physiol. Psychol., 1964, 57, 123-126.

Hurwitz, H. M. B. Method for discriminative avoidance training. Science, 1964, 145, 1070-1071.

Leaf, R. C. Acquisition of Sidman avoidance responding as a function of S-S interval. J. comp. physiol. Psychol., 1965, 59, 298300.

Meyer, D. R., Cho, C., \& Wesemann, Ann F. On problems of conditioning discriminated lever-press avoidance responses. Psychol. Rev., 1960, 67, 224-228.

Pearl, J. Intertrial interval and acquisition of a lever press avoidance response. $J$. comp. physiol. Psychol., 1963, 56, 710-712.

Pearl, J., \& Edwards, R. E. Delayed avoidance conditioning: warning stimulus (CS) duration. Psychol. Rep., 1962, 11, 375-380.

\section{Erratum}

Woodburne, L. S. Visual acuity of "Saimiri sciureus."

Psychon. Sci., 1965, 3, 307-308.

Woodburne, L, S。 Geometrical shape discrimination by "Saimiri sciureus." Psychon. Sci., 1965, 3, 309.Both articles should have contained an acknowledgement that the research was supported by National Institutes of Health Grant NB-04521-02. 